\title{
La discapacidad en las estadísticas del Impuesto sobre la Renta de las Personas Físicas
}

\author{
Disabled persons and the statistics on \\ Personal Income Tax
}

\section{Palabras clave}

Capacidad económica, certificado de discapacidad, contribuyente, estadísticas, Impuesto sobre la Renta de las Personas Físicas, Persona con discapacidad.

\section{Keywords}

Economic capacity, disability certificate, taxpayer, statistics, personal income tax, disabled person.
1. El fenómeno de la discapacidad y su relevancia para las políticas públicas ${ }^{1}$

La posesión de estadísticas sobre el fenómeno de la discapacidad en España es esencial, no sólo para conocerlo o evaluarlo, sino también para que las Políticas Públicas que, legalmente, han de destinarse a la solución del mismo, acierten en el diseño de sus instrumentos y mejoren en su eficacia y eficiencia.

En este sentido, se constata que las estadísticas del Impuesto sobre la Renta de las Personas Físicas son una fuente de información muy significativa, dada la relevancia de la discapacidad como módulo de la capacidad económica sometida a gravamen y, además, han mejorado mucho en los últimos años, debido a los trabajos de la Agencia Estatal de Administración Tributaria y el Instituto de Estudios Fiscales, por lo

I. Este artículo procede de la conferencia realizada por el autor durante la presentación del siguiente libro, del cual es coautor: Martín, I. y Carbajo, D. (20I6): La discapacidad en las estadísticas del Impuesto sobre la Renta de las Personas Físicas. Ejercicio 201 I (declaración 2OI2), Madrid: CERMI, Fundación ONCE, Ediciones Cinca.

La presentación de la obra tuvo lugar en la sede de la Fundación ONCE, Madrid, el día I 2 de julio de 2016.

\section{Domingo Carbajo Vasco}

<domingo.carbajo@correo.aeat. es>

Delegación Central de Grandes Contribuyentes. Agencia Estatal de Administración Tributaria (AEAT)
Para citar:

Carbajo Vasco, D. (20I6): "La discapacidad en las estadísticas del Impuesto sobre la Renta de las Personas Físicas". Revista Española de Discapacidad, 4 (2): 205-2I8.

Doi: <https://doi.org/I0.5 569/23405 IO4.04.02.I I > 
que se invita a los estudiosos de la discapacidad a su conocimiento y análisis.

\subsection{Desde la perspectiva jurídica}

En España, los poderes públicos vienen obligados a desarrollar variadas políticas públicas en relación con la discapacidad, incorporando diferentes instrumentos a las mismas que conllevan actuaciones presupuestarias muy diversas, tanto desde la vertiente de los gastos públicos como en el área de los ingresos y de los beneficios fiscales.

Encontrándonos en un Estado de Derecho, como proclama enfáticamente el artículo 9.I de la Constitución Española (en adelante, CE): "España se constituye en un Estado social y democrático de Derecho..." y reitera su artículo 9.I: "Los ciudadanos y los poderes públicos están sujetos a la Constitución y al resto del ordenamiento jurídico", lo primero a mencionar es la fuente jurídica de esta obligación.

Desde esta perspectiva, la obligación legal de establecer políticas públicas a favor del discapacitado halla su clave de bóveda, asimismo, en el artículo 49 de la misma Carta Magna, cuando señala:

"Los poderes públicos realizarán una política de previsión, tratamiento, rehabilitación e integración de los disminuidos físicos, sensoriales y psíquicos, a los que prestarán la atención especializada que requieran y los ampararán especialmente para el disfrute de los derechos que este Título otorga a todos los ciudadanos”.

Ciertamente, la terminología anterior ha quedado desfasada y hoy repele a nuestras sensibilidades, habiendo sido sustituida por un vocablo más moderno: el de discapacidad ${ }^{2}$

2. Conviene recordar, en este sentido, lo que dispone la disposición adicional octava de la Ley 39/2006, de I4 de diciembre, de Promoción de la Autonomía Personal y Atención a las personas en situación de dependencia:

Terminología.

"Las referencias que en los textos normativos se efectúan a 'minusválidos' y a 'personas con minusvalía', se entenderán y por sus sujetos, las personas con discapacidad.

También existe otra obligación normativa de primer orden para introducir estas políticas públicas en favor de la discapacidad, fuente jerárquicamente superior al Derecho Nacional, de acuerdo a los principios de primacía del Derecho Internacional Público que se derivan de la propia CE, artículos 93, 94.I y 96, y de la propia doctrina de su intérprete oficial y máximo: el Tribunal Constitucional.

Nos referimos a la Convención Internacional sobre los Derechos de las Personas con Discapacidad de la Organización de las Naciones Unidas (en adelante, ONU), de I 3 de diciembre de 2006 , firmada y ratificada por España y cuyo contenido forma parte íntegra de nuestro Ordenamiento Jurídico desde el día 3 de mayo de 2008.

Este Tratado International implica la existencia de una fuente jurídica de rango jerárquico superior al Ordenamiento Nacional (artículos 93, 94 y 96.I de la Constitución Española) y supone:

“... promover, proteger y asegurar el goce pleno y en condiciones de igualdad de todos los derechos humanos y libertades fundamentales por todas las personas con discapacidad, y promover el respeto de su dignidad inherente.

Las personas con discapacidad incluyen a aquellas que tengan deficiencias físicas, mentales, intelectuales o sensoriales a largo plazo que, al interactuar con diversas barreras, puedan impedir su participación plena y efectiva en la sociedad, en igualdad de condiciones con las demás".

realizadas a 'personas con discapacidad'

A partir de la entrada en vigor de la presente Ley, las disposiciones normativas elaboradas por las Administraciones Públicas utilizarán los términos 'persona con discapacidad' o 'personas con discapacidad' para denominarlas". 
De esta forma, España, como Estado de Derecho, democrático y social (artículos I. I y 9.I CE, ver supra) está obligada por sus normas nacionales y por sus compromisos jurídicos internacionales a proteger a la persona con discapacidad, a promoverla e integrarla en la sociedad, incidiendo las políticas públicas aplicadas para lograrlo en los aspectos modernos del tratamiento de la discapacidad: igualdad, inclusión, respeto y promoción.

\subsection{Consideraciones de carácter social}

\subsubsection{Introducción}

La relevancia de la discapacidad en sociedades maduras, envejecidas y con larga esperanza de vida como es la española, especialmente, tras el descenso demográfico de los tres últimos ejercicios (Instituto Nacional de Estadística, en adelante, INE; INE, 20I6), no puede extrañarnos; sin embargo, una de las características más significativas a la hora de tratar de conocer y evaluar la incidencia poblacional de la discapacidad y su distribución (territorial, social, por sexos, etc.) es la pobreza de los datos al respecto.

En España, las principales encuestas generales para las personas con discapacidad son las Encuestas sobre Discapacidades elaboradas por el INE.

La última de ellas fue la Encuesta de Discapacidad, Autonomía personal y Situaciones de Dependencia (EDAD 2008). Junto a tales trabajos, en los últimos años, el INE ha hecho por primera vez el esfuerzo de aprovechar al máximo los registros administrativos existentes para cruzarlos con encuestas consolidadas y obtener así dos nuevas operaciones periódicas que constituyen un sistema integrado de información continua y actualizada sobre personas con discapacidad y mercado laboral (INE; 20I6, 2015).

Ahora bien, tales encuestas son de valor limitado para comprender la discapacidad, pues ni siquiera cuantifican la demografía de las personas con discapacidad, es decir, el número de afectados, centran su discurso en materias laborales y son 'encuestas', con las limitaciones que tales operaciones estadísticas conllevan para el conocimiento de cualquier realidad social y económica, sobre todo, teniendo en cuenta que parten, asimismo, de la Encuesta de Población Activa.

En cualquier caso, existen una serie dificultades previas para conocer la realidad social y la demografía española de la discapacidad, como son las siguientes:

a. Ausencia de una definición homogénea de los términos 'discapacidad' y 'persona con discapacidad'. En el caso español tal carencia se ve agravada por otra circunstancia específica, como es que los criterios para delimitar la discapacidad son distintos de los utilizados para definir la dependencia3 (Ley 39/2006, de I4 de diciembre, de Promoción de la Autonomía Personal y de Atención a las personas en situación de dependencia).

Como se sabe, no son conceptos homogéneos y no hay 'pasarela' en las valoraciones entre los mecanismos para determinar y cuantificar el grado de 'discapacidad' y los ligados a la cualificación y graduación de la 'dependencia'.

b. Prevalencia reciente de los datos estadísticos relativos a la dependencia, marginando los esfuerzos y medios para construir estadísticas sobre las personas con discapacidad, dadas las dificultades terminológicas y legales existentes para poder unificar o, al menos, coordinar

\footnotetext{
3. Que, conforme al artículo 2.2 de la mencionada Ley 39/2006, es:

"El estado de carácter permanente en que se encuentran las personas que, por razones derivadas de la edad, la enfermedad o la discapacidad, y ligadas a la falta o pérdida de autonomía física, mental, intelectual o sensorial, precisan de la atención de otra u otras personas o ayudas importantes para realizar actividades básicas de la vida diaria o, en el caso de personas con discapacidad intelectual o enfermedad mental, de otros apoyos para su autonomía personal”.
} 
las fuentes de datos relativas a los dos conceptos.

\subsubsection{Datos de la dependencia}

El Instituto de Mayores y Servicios Sociales (en adelante, Imserso) tiene, entre sus misiones, la de recopilar las estadísticas relativas a la dependencia, encontrándose tales informaciones incorporadas al denominado Portal de la Dependencia e integrando el denominado Sistema de Información del Sistema para la Autonomía y Atención a la Dependencia (en adelante, Sisaad).

Aunque hemos de destacar el esfuerzo al respecto realizado por el Imserso, que permite una visión del fenómeno de la dependencia, además actualizada mensualmente, lo cierto es que no faculta conocer la demografía de la discapacidad, pues los colectivos afectados (dependientes y personas con discapacidad) son diferentes y se rigen por normas distintas.

Asimismo, no hay posibles 'pasarelas' entre los dos colectivos y sus mecanismos de valoración $\mathrm{y}$, por si esto fuera poco, los datos de la dependencia conforman un registro oficial, al originarse por la petición de los sujetos que, teóricamente, desean beneficiarse de la calificación legal de dependiente en cualquiera de sus grados.

Seguidamente, se recogen datos (Imserso, 20I6), referidos a mayo de 2016 , sobre la dependencia, a efectos puramente informativos:

- I.6ro.554 personas han solicitado la prestación de dependencia.

- I.5I2.6I7 personas han recibido dictámenes con el grado de dependencia respectivo.

- 8I7.479 personas reciben algún tipo de prestación de la Ley 39/2006.

De estas personas, el 53,94\% tienen más de 80 años, un $64 \%$ son mujeres y un $36 \%$ son hombres. De acuerdo con estos datos, la dependencia afecta más a las personas envejecidas y con alta esperanza de vida (de ahí, entre otras causas, su feminización).

\subsubsection{Datos de la discapacidad}

En cambio, la calificación de persona con discapacidad depende de un sistema de evaluación y de la atribución al sujeto de un grado de discapacidad, distinto y diferenciado en relación al de la dependencia.

Respecto de las estadísticas puras de 'personas con discapacidad', hay que tener en cuenta que el Real Decreto I97I/r999, de 23 de diciembre, de procedimiento para el reconocimiento, declaración y calificación del grado de discapacidad, es el que establece el reconocimiento de grado de discapacidad y concesión del Certificado declarativo de Grado de Discapacidad y, por lo tanto, el registro y clasificación de los mismos sería la base estadística esencial, la clave de bóveda al cuantificar y clasificar a los colectivos de tales individuos.

Esta norma considera la discapacidad como una desventaja social y médica y la cualifica según grados: desde el $33 \%$ (lo que hemos anotado como discapacidad 'simple') y más de $65 \%$ (que hemos definido como discapacidad 'cualificada').

El precitado Real Decreto I97I/I999 resulta ser, al parecer de la doctrina, una disposición anticuada, inadaptada a la moderna realidad social, clínica y jurídica de la discapacidad.

A pesar de su carácter histórico y de la unidad registral, conceptual y metodológica que supone la regulación unitaria de la discapacidad y de sus diversos grados, lo cierto es que no se posee (o, al menos, no se conoce) una estadística oficial y pública derivada de la misma que aproveche este registro, tal y como sucede, por el contrario, con el Registro Público de la dependencia, ver supra.

Sin embargo, el hecho de que a efectos tributarios se utilice el citado Real Decreto como instrumento legal para calificar a un obligado tributario en el Impuesto sobre la Renta de 
las Personas Físicas (en adelante, IRPF) como persona con discapacidad y que, asimismo, tal concepto a efectos fiscales derive de la regulación del IRPF (Alonso et al., 2009), lleva a que, si disponemos de datos estadísticos respecto de los contribuyentes con discapacidad en el IRPF, impuesto general por excelencia en el sistema tributario español y con el mayor número de declarantes (I9.750.000 declaracionesliquidaciones en Territorio Común, según datos del ejercicio 20I4, declaración 20I5), podemos convertir en estadística de la discapacidad a la estadística de las personas declarantes con discapacidad en el IRPF, aunque, lógicamente, tal identificación no esté exenta de problemas y de limitaciones, empezando por el hecho de que una estadística (como es la del IRPF) elaborada desde fuentes y con objetivos tributarios no puede comprender datos de la discapacidad sin regulación en la normativa del IRPF u ofrecer información sobre aspectos, verbigracia, epidemiológicos, que no aparecen reflejados en las declaraciones tributarias.

Por lo tanto, podemos afirmar que la estadística de las personas con discapacidad en España o, al menos, las estadísticas que con mayor amplitud demográfica informan sobre tal circunstancia en España, resultan ser las estadísticas del IRPF, pues el artículo 72.I del Reglamento del IRPF, Real Decreto 439/2007, de 30 de marzo $^{4}$, parte de los certificados emitidos conforme

4. Acreditación de la condición de persona con discapacidad y de la necesidad de ayuda de otra persona o de la existencia de dificultades de movilidad

I. A los efectos del Impuesto sobre la Renta de las Personas Físicas, tendrán la consideración de persona con discapacidad aquellos contribuyentes con un grado de minusvalía igual o superior al 33 por ciento.

El grado de minusvalía deberá acreditarse mediante certificado o resolución expedida por el Instituto de Migraciones y Servicios Sociales o el órgano competente de las Comunidades Autónomas. En particular, se considerará acreditado un grado de minusvalía igual o superior al 33 por ciento en el caso de los pensionistas de la Seguridad Social que tengan reconocida una pensión de incapacidad permanente total, absoluta o gran invalidez y en el caso de los pensionistas de clases pasivas que tengan reconocida una pensión de jubilación o retiro por incapacidad permanente para el servicio o inutilidad. Igualmente, se considerará acreditado un grado de minusvalía igual o superior al 65 por ciento, cuando se trate de personas cuya incapacidad sea declarada judicialmente, aunque no alcance dicho grado. al precitado Real Decreto I97I/I999 por el Imserso o la Consejería competente en materias sociales de las comunidades autónomas (en adelante, CCAA) para establecer cuándo un obligado tributario está calificado como 'persona con discapacidad'. Además, el criterio, graduación y certificación de la discapacidad, según el IRPF, se ha convertido en la norma marco para determinar y probar la discapacidad en todo el Ordenamiento Tributario español.

\subsubsection{Algunas conclusiones}

- Las estadísticas españolas oficiales relativas a las personas con discapacidad son pobres y necesitan homogeneización y periodicidad. Hace falta una estadística anual con criterios homogéneos, estadísticamente hablando (INE).

- La estadística de las personas con discapacidad en España resulta ser, en realidad, la estadística del IRPF, ya que no hay otra entidad o fuente que proporcione información 'pura' con datos relativos al grado de discapacidad; de ahí también su relevancia pero, asimismo, su insuficiencia y sus restricciones informativas.

En cualquier caso, conviene insistir en la necesidad de disponer de una estadística oficial y pública sobre la discapacidad y las personas con discapacidad en España, actualizada periódicamente y que englobe aspectos no exclusivamente tributarios, ya que como hemos señalado en otra obra:

"Es de sobra conocido, que la primera acción para resolver, solucionar, paliar, mejorar, etc. un fenómeno social (con claras implicaciones económicas y morales) como es el de la discapacidad es su conocimiento y, en particular, la delimitación y cuantificación de los sujetos afectados por esta problemática y la evaluación de sus consecuencias económicas; por ello, cualquier información estadística como la planeada en este estudio, a partir de fuentes fiscales, resulta ser por sí misma un 'plus' para mejorar nuestra aprehensión de 
la realidad de la discapacidad y, a partir del mismo, desarrollar las políticas públicas que nuestra CE exige.

Sin embargo, mientras que en los últimos años se han desarrollado importantes esfuerzos y trabajos a la hora de disponer información acerca de la dependencia (cuestión, como hemos indicado anteriormente, relacionada, con zonas comunes, pero distinta de la discapacidad), esfuerzos vinculados a la preparación e implementación de la precitada Ley 39/2006, Ley de Dependencia; lo cierto es que, acerca de la discapacidad, existe una menor información cuantitativa, limitación que también este trabajo quiere ayudar a suplir” (Martín y Carbajo, 20I6: 2I).

Por otra parte, recopilar estadísticas y datos acerca de las personas con discapacidad es una obligación derivada de la Convención de la ONU sobre los Derechos de las Personas con discapacidad, ver supra, cuyo artículo 3 I señala:

“...los Estados Partes recopilarán información adecuada, incluidos datos estadísticos y de investigación, que les permitan formular y aplicar políticas, a fin de dar efectos a la presente Convención".

Todo ello, bajo la rúbrica: Recopilación de datos y estadísticas.

\section{El impacto económico y fiscal de la discapacidad}

La dependencia y la discapacidad tienen una fuerte incidencia económica, tanto pública (políticas sociales, sanitarias y asistenciales, cada vez más relevantes en el Estado Social, artículo I.I CE y que han sido objeto de un inaceptable recorte durante la denominada "era de los ajustes", evaluando la reducción en un 8,3 \% en políticas de dependencia -Foessa, 20I4; OxfamIntermón, 2013-), como privada en términos de inversiones (domótica, sanidad, accesibilidad, etc.) y en volumen de gasto.

La discapacidad implica mayores gastos tanto por el sujeto afectado como por la existencia de sujetos con discapacidad que son atendidos económicamente por otras personas, generalmente familiares, al no poder obtener recursos suficientes por sí solos.

Esta menor capacidad económica producida por los gastos necesarios para atender la discapacidad ha llegado a ser cuantificada en varios estudios (Ayuntamiento de Barcelona, 2006; Confederación Española de Organizaciones a favor de las Personas con Discapacidad Intelectual o del Desarrollo, Feaps, 20I4).

Entre sus conclusiones más llamativas destaca que una familia con una persona con discapacidad intelectual soporta un sobreesfuerzo económico anual que excede de 24.000 euros, lo que supera al salario medio en España en esa fecha (fijado en 22.727 euros).

La existencia de personas con discapacidad conlleva importantes gastos e inversiones para los sujetos afectados directa o indirectamente (generalmente familiares), pero también para los poderes públicos y, en consecuencia, la capacidad económica sometida a imposición (artículos 3I.I de la $\mathrm{CE}^{5}$ y 2.I de la Ley 58/2003, de I 7 de diciembre, General Tributaria, norma básica del Ordenamiento Tributario español ${ }^{6}$ ) se ve afectada, ergo el sistema tributario tiene que tomar en consideración esta reducción de la capacidad

5. Todos contribuirán al sostenimiento de los gastos públicos de acuerdo con su capacidad económica mediante un sistema tributario justo inspirado en los principios de igualdad y progresividad que, en ningún caso, tendrá alcance confiscatorio. 6. Los tributos son los ingresos públicos que consisten en prestaciones pecuniarias exigidas por una administración pública como consecuencia de la realización del supuesto de hecho al que la ley vincula el deber de contribuir, con el fin primordial de obtener los ingresos necesarios para el sostenimiento de los gastos públicos.

Los tributos, además de ser medios para obtener los recursos necesarios para el sostenimiento de los gastos públicos, podrán servir como instrumentos de la política económica general y atender a la realización de los principios y fines contenidos en la Constitución. 
económica a la hora de configurar el sistema tributario mediante su llamada función extrafiscal, artículo 2.I, segundo párrafo, Ley General Tributaria y la implementación de un elenco de beneficios fiscales en favor de las personas con discapacidad.

Pero, no solamente la discapacidad conlleva una menor capacidad económica para los sujetos afectados y los que conviven con ellos, sino que también son necesarias inversiones y gastos extraordinarios para lograr que la persona con discapacidad esté incluida en el entramado social y en posiciones de igualdad.

De esta forma, el sistema tributario debe atender a la persona con discapacidad desde dos frentes:

a. El círculo ‘subjetivo' de la discapacidad que debe manifestarse en tributos personales, caso del Impuesto sobre la Renta de las Personas Físicas (IRPF), y

b. El círculo 'objetivo' de la discapacidad que debía centrarse, por ejemplo, en los gravámenes sobre el consumo, tipo Impuesto sobre el Valor Añadido (en adelante, IVA).

Desgraciadamente, nuestro sistema tributario y nuestras estadísticas se centran más en la vertiente a) que en la b) y, sin embargo, en una visión moderna de la discapacidad puede ser más relevante la acción sobre inversiones (accesibilidad) y en gastos que la modulación de la capacidad económica (renta) sometida a imposición (Carbajo, 2006: 8I-88).

\section{Estadísticas tributarias del IRPF y discapacidad}

Al respecto, empezamos con tres ideas significativas:

a. Las estadísticas tributarias proporcionan una visión moderna, actualizada periódicamente y muy vinculada a la realidad sobre la actividad económica y la sociedad española.

Las fuentes estadísticas más relevantes en materia del IRPF son el portal de la Agencia Estatal de Administración Tributaria (en adelante, AEAT), www.agenciatributaria. es, pestaña 'Estadísticas', 'Estadísticas por impuesto'/'IRPF y Patrimonio'; la Base de Datos del Sector Público, Badespe, que publica el Instituto de Estudios Fiscales (en adelante, IEF), www.ief.es, Badespe y, de manera secundaria, con alguna precisión o detalle relevante, la publicación de la Dirección General de Tributos, Estadísticas del IRPF y del Impuesto sobre el Patrimonio, la cual tiene los graves problemas de su irregularidad en la publicación y el atraso de los años expuestos (la última hace referencia al período 2007), así como otras publicaciones de la propia AEAT, por ejemplo, su Memoria Anual.

b. La AEAT ha realizado y lleva ejecutando un programa estadístico muy significativo, de alta calidad, cada vez más amplio, elaborado y riguroso (AEATa, 20I6).

c. El IRPF es un gravamen esencial en las sociedades democráticas y fundamental para el funcionamiento del sistema tributario español: primero en importancia recaudatoria; primero en reflejar la realidad social por número de contribuyentes (I9.750.000 declarantes, aproximadamente); primero en su impacto en los debates de política fiscal, etc.

En suma, las estadísticas tributarias deben ser objeto de una mayor atención por parte de los estudios de la realidad social y económica española, así como de su evolución.

Pero, además, las estadísticas del IRPF permiten el análisis del microcosmos social español, pues su desglose alcanza a distribuciones por municipios, comunidades autónomas, administraciones de Hacienda, familias, edades, sexo, etc. 
De hecho, es posible explotar mucho más las estadísticas del IRPF y obtener nuevos datos, cruces de datos o mayores detalles de los mismos, verbigracia, como ejemplo de esto último, muchas estadísticas se presentan desglosadas por las I 7 comunidades autónomas, pero se pueden dividir por provincias, por los municipios de los declarantes, etc.

Asimismo, es importante resaltar que estas estadísticas son anuales y se actualizan periódicamente, siguiendo asimismo criterios homogéneos y metodologías comunes, lo que permite ya un conocimiento histórico de la evolución de ciertos datos sociales, desde el salario medio del español hasta la distribución por sexos de las rentas declaradas.

En este sentido, cabe aplaudir el trabajo de análisis estadístico 'fino' que el IEF lleva desarrollando desde hace muchos años sobre las estadísticas tributarias y, en general, sobre las bases de datos públicas, integrando las mismas en Badespe o Base de Datos Económicos del Sector Público Español (Instituto de Estudios Fiscales, 2016).

Los trabajos del IEF sobre el IRPF son esenciales, al permitir disponer de un análisis mucho más minucioso de los declarantes del IRPF y, por la misma razón, de la situación de las personas con discapacidad en el impuesto. Estos trabajos estadísticos del IRPF se presentan en forma de su 'Panel' de declarantes (Pérez López et al., 2016a) y su 'Muestra' (Pérez López et al., 20I6b), de las cuales ya disponemos de datos relativos a 20I3 (declaración 20I4).

En las estadísticas del IRPF del ejercicio 20I4 (declaración 20I 5), últimas publicadas por la AEAT, encontramos informaciones muy significativas para el análisis de la discapacidad, por ejemplo:

- $\quad$ Que el 9\% de las declaraciones del IRPF manifiestan que incluyen una persona con discapacidad, es decir, que sobre I9.399.020 declarantes, I.8 I4.I93 declaraciones del impuesto reflejan personas con discapacidad.
Sin embargo, el impacto de la discapacidad en el impuesto es mayor, porque las declaraciones que rellenan el mínimo por discapacidad estatal, suponen I.746.809 declarantes.

La discapacidad tiene también un gran impacto económico; de esta forma, respecto al mínimo por discapacidad, el importe total es de 8.348 millones de euros, aparece en I.746.809 declaraciones y el importe medio por declaración es de 4.779 euros.

- Que no parecen estar funcionando bien, o no disponen de la estructura legal adecuada para ser incentivadores, los sistemas de previsión social vinculados a reducciones en la base imponible y a la discapacidad, escasamente usados por los obligados tributarios.

Así, la reducción por aportaciones y contribuciones a sistemas de previsión social de personas con discapacidad aparece en el $0,07 \%$ de las declaraciones del IRPF, I 3.582 declaraciones, con un importe total de 30,2 millones de euros y un importe medio de 2.224 euros por declaración.

Por su parte, la reducción por aportaciones a los patrimonios protegidos de las personas con discapacidad se encuentra en el $0,02 \%$ de las declaraciones, 2.0I 2 declaraciones, con un importe total de II, 3 millones de euros y un importe medio de 2.224 euros por declaración.

- Que la discapacidad se refleja en diferentes parámetros del IRPF, ya que:

"La distinta condición con la que se presentan las personas con discapacidad en la declaración de IRPF, ha permitido crear unas categorías según quienes sean las personas con discapacidad integradas en la declaración: discapacidad en el primer titular (declarante), en las declaraciones conjuntas discapacidad en el segundo titular (cónyuge), discapacidad en los descendientes, en los ascendientes o en 
varias personas de forma simultánea en una declaración”. (Martín y Carbajo, 20I6: 88).

De esta forma, si bien sólo, aproximadamente, el $6 \%$ de los declarantes afirman estar discapacitados, el impacto de la discapacidad en otros parámetros del impuesto eleva esta cifra al $9 \%$ del total de declaraciones, I.8I4.I93, y así sucesivamente.

En suma, las estadísticas del IRPF conforman una fuente de datos de la mayor relevancia para conocer los fenómenos sociales de España y la discapacidad está entre uno de los más significativos de estos, por lo que debería ser integrado sistemática y periódicamente en las publicaciones y análisis estadístico-tributarios.

Sin embargo, tal planteamiento no existía para la AEAT antes de 20I4.

\section{La reacción. Las estadísticas oficiales sobre discapacidad del IRPF publicadas por la AEAT}

Pues bien, estamos de enhorabuena, pues para los años 20I3 y 2014 sí disponemos de un análisis de las personas con discapacidad en las estadísticas tributarias (que es como decir en las estadísticas españolas, ver supra), al hacerse públicas por la AEAT datos al respecto en el IRPF (AEAT, 20I6b).

La cual, según se indica en su 'Presentación':

"Se añade a la serie de estadísticas tributarias una nueva publicación denominada Estadística de los declarantes con discapacidad del Impuesto sobre la Renta de las Personas Físicas. El objetivo de dicha estadística es conocer las características personales y familiares del conjunto de declarantes en las que, o bien el titular, o bien alguna de las personas dependientes del mismo (ascendiente o descendiente) tienen alguna discapacidad reconocida que proporcione al declarante la posibilidad de aplicar alguna de las medidas contempladas en la normativa del impuesto para minorar la carga impositiva del colectivo afectado.

Para profundizar en el conocimiento de las personas con discapacidad y sus circunstancias, en la medida en que dichas circunstancias se hayan puesto de manifiesto en las declaraciones de IRPF, se contabilizan las distintas situaciones de discapacidad puestas de relieve en la declaración. Sin embargo, este recuento no debe considerarse un censo de personas con discapacidad, porque faltarían los no declarantes de IRPF, los que no hayan hecho uso de sus beneficios fiscales, así como todas las personas residentes en País Vasco y Navarra que quedan fuera del ámbito territorial del impuesto".

En estas estadísticas del IRPF de las personas con discapacidad, se presentan sus características demográficas principales: el género, la edad, tipo de dependencia (simple, simple con movilidad reducida, cualificada) y la comunidad autónoma declarada por el titular de la declaración.

La distinta condición con la que se presentan las personas con discapacidad en la declaración de IRPF ha permitido crear unas categorías según quienes sean las personas con discapacidad integradas en la declaración: discapacidad en el primer titular (declarante), en las declaraciones conjuntas discapacidad en el segundo titular (cónyuge), discapacidad en los descendientes, en los ascendientes o en varias personas de forma simultánea en una declaración (múltiples situaciones de discapacidad).

De esta manera, desde la perspectiva de la declaración, se ofrecen las categorías de situaciones de discapacidad, el porcentaje de discapacidad, la relación de parentesco con el titular principal de la declaración, etc. Adicionalmente, se incluye un bloque de información destinado a la integración del colectivo de estudio con el total de declarantes del IRPF (objeto de publicación en otra estadística).

En este sentido, la información proporcionada 
es común a la que se presenta en la estadística general, sin embargo, añade contenidos adicionales, por ejemplo, una tabla con las medidas fiscales orientadas a la protección del colectivo afectado y una información sobre las rentas exentas percibidas por las personas relacionadas en la declaración, sean titulares, descendientes o ascendientes. ${ }^{7}$

Sólo cabe felicitar a la Secretaría de Estado de Hacienda, a la AEAT y al Servicio de Estadísticas de la AEAT por esta magnífica labor.

\section{Labores de futuro}

Pero la publicación anterior, aun importante y muy positiva para el conocimiento de la discapacidad en España, no es bastante para establecer la situación de la misma; en primer lugar, porque sólo poseemos los datos de dos ejercicios: 20I3 y 2014 y, en consecuencia, hay que aguardar a la publicación periódica de más ejercicios sobre tales estadísticas, para realizar análisis comparativos temporales más amplios y, en general, creemos necesario:

I. Reconocer que el conocimiento estadístico de la discapacidad y sus diferentes variables, así como su distribución territorial y de otro tipo, verbigracia por decilas de renta, constituye un poderoso instrumento para que las autoridades públicas puedan mejorar la eficacia y eficiencia de las políticas sociales destinadas a la información, prevención, rehabilitación y solución, en su caso, de las diferentes discapacidades.
7. www.agenciatributaria.es/AEAT/Contenidos_Comunes/ La_Agencia_Tributaria/Estadisticas/Publicaciones/sites/discapacidad/20I $4 /$ home.html
2. La discapacidad no ha explotado sistemáticamente (al igual que otras políticas sociales) el potencial de información estadística y de conocimiento de esa realidad que supone la existencia en el sistema tributario español de múltiples parámetros en tributos principales, por ejemplo, el IRPF y el IVA, que aparecen vinculados a aquella y que modulan la capacidad económica sometida a gravamen en cada caso.

3. Sería necesario establecer un programa estadístico de explotación sistemática de estadísticas fiscales afectadas por la discapacidad o de interés para el conocimiento de esta variable socioeconómica, demográfica y epidemiológica y coordinarlas con otras fuentes estadísticas del INE, de Ministerio de Asuntos Sociales, de las comunidades autónomas, etc.

4. Desgraciadamente, las estadísticas de gravámenes esenciales para obtener tal información y permitir su estudio no disponen de datos desagregados relativos a la discapacidad. Esto sucede por ejemplo en el IVA.

5. Tan solo en el IRPF las casillas del modelo de declaración-liquidación del tributo, la incidencia de la discapacidad en múltiples parámetros de la liquidación del impuesto y la propia abundancia, homogeneización y calidad de los datos permiten explotar las estadísticas del IRPF al servicio de la discapacidad.

6. Sin embargo, no hay un programa integrado y planificado que permita, no sólo ampliar este tipo de trabajos a otros gravámenes, sino relacionar las estadísticas fiscales en materia de discapacidad con otro tipo de fuentes informativas acerca de esta circunstancia, por ejemplo, el SAAD.

7. Es preciso coordinar mejor los datos estadísticos sobre discapacidad y personas con discapacidad que existen en fuentes diversas, unificando metodologías y conceptos. 
8. Por ello, hay que preparar las declaracionesliquidaciones de otros gravámenes, caso del IVA, para poner disponer de una adecuada información cuantitativa acerca de la discapacidad y las personas con discapacidad.

9. Al igual que sucede con otras variables, supuesto paradigmático del sexo, es posible desglosar las estadísticas fiscales atendiendo a la discapacidad de los obligados tributarios y obtener información sobre la discapacidad muy relevante para las políticas sociales y de otro tipo, por ejemplo, la propia política fiscal.

Io. El IEF debería introducir nuevos datos sobre discapacidad en sus publicaciones sobre 'Muestra' y 'Panel' de declarantes del IRPF.

I I. En cualquier circunstancia, sería crítico que el análisis cuantitativo de la discapacidad y de las personas con discapacidad a partir de las estadísticas tributarias publicadas por la AEAT se extendiese a otros impuestos $y$, asimismo, a otras instituciones que se encargan de la aplicación de los tributos, desde las vinculadas a entidades locales a las diputaciones forales.

I2. Sería adecuado también integrar los estudios de la discapacidad en datos fiscales declarados por los obligados tributarios con otro tipo de información de contenido fiscal, supuesto de la derivada de los Presupuestos de Beneficios Fiscales tanto los relativos al Estado Central como los aprobados por las diferentes CCAA.

I3. La incorporación de esta nueva variable, la discapacidad, a la hora de presentar y analizar las estadísticas fiscales sería relativamente fácil y no supondría un gran coste para el presupuesto público. Para ello, se debería partir del estudio de los diferentes modelos de autoliquidación y declaraciones informativas a través de los cuales se elaboran las estadísticas tributarias en España.
I4. Hay muchos parámetros en la liquidación del IRPF, donde la existencia de discapacidad en el contribuyente o en sus allegados tiene importancia en la carga tributaria del impuesto y, sin embargo, no se dispone del medio estadístico (casilla en la declaración-liquidación) que permita evaluar su incidencia y su eficiencia o reflexionar sobre el cumplimiento de sus finalidades de política fiscal o extrafiscal.

I 5. Es de destacar cómo la diferencia cuantitativa entre las variables del IRPF donde se incluye el grado de discapacidad situado entre el 33 y el $65 \%$ y la correspondiente a las situaciones de discapacidad cualificada, más del $65 \%$, resulta escasa en términos de cifras legales y, sin embargo, la realidad muestra que el salto en la reducción de capacidad económica que supone un grado de discapacidad elevado es muy significativo, por lo que la normativa del IRPF debería tenerlo en cuenta.

16. Lo mismo cabe decir del número de personas con discapacidad que 'dependen' de un obligado tributario principal, pues la reducción de la capacidad económica que conlleva la existencia de varias de estas personas 'dependientes' es muy superior a una progresión aritmética de su número.

I7. Hay muchos parámetros en la liquidación del IRPF donde la existencia de discapacidad en el contribuyente o en sus allegados tiene importancia en la carga tributaria del impuesto y, sin embargo, no se dispone del medio estadístico (casilla en la declaración-liquidación) que permita evaluar su incidencia y su eficiencia o reflexionar sobre el cumplimiento de sus finalidades de política fiscal o extrafiscal.

I8. En materia de deducciones en la cuota estatal, a pesar de su relevancia como instrumento extrafiscal, la información que reflejan las estadísticas del IRPF, es totalmente insuficiente ya que, por ejemplo, es imposible distinguir en el seno de las mismas aspectos directamente relacionados con la discapacidad. 
I9. En materia de deducciones en la cuota autonómica del IRPF ligadas a la discapacidad, si bien las CCAA han ejercido con regularidad su capacidad normativa al respecto, su redacción legal es tan compleja y los requisitos que plantea su aplicación tan intrincados, que pocos contribuyentes han hecho uso legalmente de las mismas, por lo que su eficacia es muy reducida.

20. Los datos estadísticos de las deducciones autonómicas del IRPF para las personas con discapacidad manifiestan, tanto en términos de contribuyentes beneficiados como respecto a su incidencia recaudatoria, que son más bien un instrumento de propaganda del gobierno autonómico de turno que un verdadero mecanismo fiscal en favor de la reducción de la capacidad económica que conlleva la discapacidad.

2I. Sería necesario continuar la explotación de las estadísticas del IRPF de períodos impositivos posteriores al año 2013 para comparar la información sobre discapacidad y disponer de series homogéneas largas. 
Referencias bibliográficas

Alonso-Olea, B. et al. (2009): La Protección de las Personas con Discapacidad y en Situación de Dependencia en el Derecho de la Seguridad Social y en el Derecho Tributario, Pamplona: Aranzadi.

Ayuntamiento de Barcelona, Instituto Municipal de Personas con Discapacidad y Antares Consulting (2006): Estudio del agravio comparativo económico de las personas con discapacidad en la Ciudad de Barcelona, Barcelona: Ayuntamiento de Barcelona e Instituto Municipal de Personas con Discapacidad.

Carbajo, D. (2006): "La situación fiscal del discapacitado: algunas reflexiones". Crónica Tributaria, II9: 8I-88.

Agencia Estatal de Administración Tributaria (AEAT) (20I6a): Memorias y estadísticas tributarias (en línea). <www.agenciatributaria. es/AEAT.internet/Inicio/La_Agencia_Tributaria/ Memorias_y_estadisticas_tributarias/ Estadisticas/Estadisticas.shtml $>$, acceso 2 I de julio de 2016.

Agencia Estatal de Administración Tributaria (AEAT) (2016b): Estadísticas de los declarantes con discapacidad (en línea). <www.agenciatributaria.es/AEAT.internet/ datosabiertos/catalogo/hacienda/Estadistica_ de_los_declarantes_con_discapacidad_del_ IRPF.shtml>, acceso 2 I de julio de 2016.

Confederación Española de Organizaciones a favor de las Personas con Discapacidad Intelectual o del Desarrollo, Feaps (201 5): El sobreesfuerzo económico que la discapacidad intelectual o del desarrollo ocasiona en la familia en España 2014 (en línea). <http://www.feaps.org/archivo/ centro-documental/doc_download/548-.html>, acceso 2 I de julio de 2016.

España. Real Decreto 439/2007, de 30 de marzo, por el que se aprueba el Reglamento del Impuesto sobre la Renta de las Personas Físicas y se modifica el Reglamento de Planes y Fondos de Pensiones, Boletín Oficial del Estado, 3 I de marzo de 2007, núm. 78, pp. I4097-I4I49.
España. Real Decreto I97I/I999, de 23 de diciembre, de procedimiento para el reconocimiento, declaración y calificación del grado de minusvalía., Boletín Oficial del Estado, 26 de enero de 2000, núm. 22, pp. 33I7-34IO.

Foessa (20I4): VII Informe FOESSA sobre exclusión y desarrollo social en España (en línea). <http://www.foessa2oI 4.es/informe/>, acceso 2 I de julio de 2016.

Imserso (2016): Información Estadística del Sistema para la Autonomía y Atención a la Dependencia (en línea). <www.dependencia. imserso.es/dependencia_ог/documentacion/ estadisticas/est_inf/inf_gp/20I6/index.htm>, acceso 2 I de julio de 2016 .

Instituto de Estudios Fiscales (2016): Badespe, Base de Datos del Sector Público Español (en línea) $<$ www.ief.es/destacados/badespe.aspx>, acceso 2 I de julio de 2016.

Instituto Nacional de Estadística, INE (2016): El Empleo de las personas con discapacidad (en línea). <www.ine.es/inebaseDYN/cp3032I/ cp_inicio.htm>, acceso 20 de julio de 2016 .

Instituto Nacional de Estadística, INE (2O I 5): El Salario de las personas con discapacidad (en línea). <www.ine.es/prensa/np956.pdf>, acceso 20 de julio de 2016 .

Martín, I. y Carbajo, D. (2016): La discapacidad en las estadísticas del Impuesto sobre la Renta de las Personas Físicas. Ejercicio 20 I I (declaración 20I2), Madrid: CERMI, Fundación ONCE, Ediciones Cinca.

Oxfam-Intermón (2013): La trampa de la austeridad (en línea). <www.oxfam.org/sites/ www.oxfam.org/files/bp 74-cautionary-taleausterity-inequality-europe-I 209I3-es.pdf>, acceso 20 de julio de 2016 .

Pérez López, C. et al. (2016a): Panel de Declarantes de IRPF I999-20I2: Metodología, estructura y variables (en línea). <www.ief.es/documentos/ recursos/publicaciones/documentos_ 
trabajo/20I6_II.pdf>, acceso 20 de julio de 2016.

Pérez López, C. et al. (2016b): La muestra del IRPF de 20I3: descripción general y principales magnitudes (en línea). <www. ief.es/documentos/recursos/publicaciones/ documentos_trabajo/20I6_09.pdf >, acceso 20 de julio de 2016. 